\title{
A Judicialização de medicamentos no estado da Bahia: os números no período de 2014 a 2017
}

The judicialization of medications in the state of Bahia, Brazil: the numbers from 2014 to 2017

La judicialización de los medicamentos en el estado de Bahía, Brasil: las cifras en el período de 2014 a 2017

Poliana Brito Barbosa ${ }^{1}$

Simone Cerqueira Machado Alves²

\begin{abstract}
Resumo
Objetivo: o trabalho é dedicado ao tema da judicialização no estado da Bahia, visando analisar sua dimensão e trajetória entre 2014 e 2017, com destaque para os números relacionados à assistência farmacêutica. Metodologia: estudo de caso em que se utilizou a base de dados do Núcleo de Atendimento à Judicialização da Saúde (NAJS) do estado da Bahia. Resultados: curva crescente da judicialização no âmbito da assistência farmacêutica; predomínio de ações individuais; incremento de gastos com a judicialização no componente especializado. Conclusão: a judicialização no estado da Bahia segue a tendência nacional de aumento, sem que se vislumbre uma adequada discussão entre o Poder Público, o Judiciário e a sociedade.
\end{abstract}

Palavras-chave: Judicialização da saúde. Política pública. Assistência farmacêutica.

\begin{abstract}
Objective: the work is devoted to the subject of judicialization in the state of Bahia, aiming to analyze its size and trajectory between 2014 and 2017, with emphasis on the numbers related to pharmaceutical care. Methodology: a case study in which the database of the nucleus of care for the judicialization of the state of Bahia was used. Results: increasing curve of judicialization in the scope of pharmaceutical care; predominance of individual actions; reduction of costs with judicialization in the specialized component. Conclusion: the judicialization in the state of Bahia follows the national trend of increase, without a glimpse of an adequate discussion between the public power, the Judiciary and the society.
\end{abstract}

Keyword: Health's judicialization. Public policy. Pharmaceutical assistance.

\footnotetext{
${ }^{1}$ Médica reguladora no Núcleo de Atendimento a Judicialização na Saúde (NAJS) da Secretaria de Saúde do Estado da Bahia (SESAB), Salvador, Bahia, Brasil; médica especialista em Direito e Saúde pela Escola de Magistratura da Bahia (EMAB); especialista em Cirurgia de Cabeça e Pescoço pela Sociedade Brasileira de Cirurgia de Cabeça e Pescoço (SBCCP); mestranda em Administração pela Universidade Federal da Bahia. E-mail: poliana.barbosa@saude.ba.gov.br ${ }^{2}$ Farmacêutica no Núcleo de Atendimento a Judicialização na Saúde (NAJS) da Secretaria de Saúde do Estado da Bahia (SESAB), Salvador, Bahia, Brasil; farmacêutica com habilitação em Análises Clínicas pela Universidade Federal da Bahia; especialista em Gestão da Assistência Farmacêutica pela Universidade Federal de Santa Catarina; especialista em Gestão de serviços de Saúde pela Escola Estadual de Saúde Pública da Bahia. E-mail: simone.machado1@saude.ba.gov.br
} 


\section{Resumen}

Objetivo: el trabajo se dedica al tema de la judicialización en el estado de Bahía, con el objetivo de analizar su tamaño y trayectoria entre 2014 y 2017, con énfasis en las cifras relacionadas con la atención farmacéutica. Metodología: un estudio de caso en el que se utilizó la base de datos del núcleo de atención para la judicialización del estado de Bahía. Resultados: aumento de la curva de judicialization en el ámbito de la atención farmacéutica; predominio de acciones individuales; reducción de costes con judicialización en el componente especializado. Conclusión: la judicialización en el estado de Bahía sigue la tendencia nacional de aumento, sin vislumbrar una discusión adecuada entre el poder público, el poder judicial y la sociedad.

Palabra clave: Judicialización de la salud. Política pública. Asistencia farmacéutica.

\section{Introdução}

Pelos critérios da Organização Mundial da Saúde (1), saúde seria uma "situação de perfeito bem-estar físico, mental e social". Contudo, até mesmo essa definição, avançada para a época em que foi criada, pode ser considerada ultrapassada, visto ser impossível alcançar uma situação perfeita de bem-estar. Existem fatores contribuintes para se ter saúde, tais como como água potável, esgotamento sanitário, hábitos de vida saudáveis, dentre outros. Porém, apenas baseando-se em conceitos de saúde como ausência de doença, o direito fundamental à saúde, no Brasil, tem previsão no artigo 196 da Constituição da República Federativa do Brasil de 1988 (CRFB), que assim dispõe: “a saúde é direito de todos e dever do Estado, garantido mediante políticas sociais e econômicas que visem a redução do risco de doença" (2).

A partir da apropriação desse caráter igualitário, integral e universal, contido na Carta Magna e que são pilares do Sistema Único de Saúde (SUS), a população encontrou na judicialização uma ferramenta para sua efetivação (3), tendo esse fenômeno se iniciado com o caso HIV-Aids (4), pleiteado por meio de tutela coletiva. O protagonismo pela tutela coletiva não se perpetuou, porém, sendo as tutelas em saúde eminentemente individuais.

A judicialização da saúde pública é a última alternativa à qual os usuários recorrem para a obtenção de medicamentos ou tratamentos negados pelo SUS, ou por falta de previsão na Relação Nacional de Medicamentos (Rename) e Relação Nacional de Serviços de Saúde (Renases), ou por questões orçamentárias, ou seja, por estar disponível por meio de política pública, porém, com demanda superior à oferta ou em desabastecimento. É reflexo de um sistema de saúde deficitário, que não consegue concretizar a contento a proteção desse direito fundamental dentro de determinadas áreas do direito à saúde (5).

O fenômeno vem crescendo, ocorre em todos em estados brasileiros (6) e tem atraído 
maior atenção dos magistrados sobre o impacto negativo que causa na programação do orçamento para a saúde (7). O último relatório divulgado pelo Conselho Nacional de Justiça (CNJ) (8) sobre a judicialização na saúde aponta um crescimento de aproximadamente 130\% nas demandas de primeira instância entre 2008 e 2017. A pesquisa constatou que, em 2008, havia 3.066.526 processos tramitando em segunda instância, enquanto nos anos seguintes esse número foi aumentando gradativamente, com 3.132.664 em 2009, e 4.373.418 em 2017, observando-se um aumento de cerca de $85 \%$ de demandas relativas ao direito à saúde. Segundo o relatório, tal crescimento é mais do que o dobro do observado no período para o total de processos, que foi de $40 \%$.

Quanto às ações sobre saúde demandadas nos Tribunais de Justiça (TJ), dos nove estados da região Nordeste do Brasil, houve um aumento de cerca de $70 \%$ se observados os relatórios mencionados: 10.130 ações judiciais até 2011, e 17.026 ações judiciais até 2014 $(9,10)$.

O entendimento no Executivo Federal é que o país lida, no SUS, com a judicialização do acesso pontual de medicamentos, que estão na rede nacional, e de uma quantidade enorme de pequenas cirurgias, fruto da desorganização do sistema, da falta de informatização e do subfinanciamento.

A literatura demonstra o crescimento do número de ações judiciais em saúde em inúmeras unidades da federação: Rio de Janeiro (11,12); São Paulo (13); Distrito Federal (14, 15); Minas Gerais (16); Santa Catarina (17) e Ceará (18).

A judicialização da saúde pública no Brasil tem desdobramentos importantes sobre o cumprimento orçamentário do Estado e nas relações entre os três poderes, devendo, por isso, ser analisada com atenção por pesquisadores de áreas como a saúde, o direito e a administração pública. Sobre o impacto orçamentário, é notado que o fenômeno vem associado ao comprometimento cada vez maior dos recursos destinados à promoção, proteção e recuperação da saúde, pilares da política pública do SUS (10). Esse assunto torna-se ainda mais relevante para os estados em um momento de maior contingência orçamentária e com o Executivo submetido ao novo limite de teto de gastos. Estima-se que o SUS vai perder algo em torno de $R \$ 417$ bilhões durante a vigência da Emenda Constitucional no 95. Se o quadro da saúde pública já é cronicamente ruim, ele tende a ficar pior $(19,20)$.

O presente trabalho dedica-se ao tema da judicialização da saúde pública no estado da 
Bahia, com o objetivo de analisar sua dimensão e trajetória no período compreendido entre 2014 a 2017 e os números relacionados à assistência farmacêutica.

\section{A judicialização da política de saúde no Brasil}

Nota-se que há uma ampla discussão sobre a judicialização da saúde nos últimos anos, de modo que o assunto, dentro da perspectiva da judicialização da política, tem dominado as discussões no meio jurídico e na saúde, mas tendo presença na Administração Pública ainda de modo incipiente. O termo judicialização da política tem sido utilizado no que diz respeito à tentativa de resolução de conflitos em áreas cuja atuação é majoritariamente política, assim como para sinalizar a crescente presença das instituições judiciais e de seus procedimentos nessas áreas (21).

A origem desse termo advém de trabalho desenvolvido por Tatte e T. Vallinder (22) na obra The Global Expansion of Judicial Power, quando conceituaram a judicialização da política empreendida por meio de uma análise dos cenários e condições políticas para sua ocorrência e expansão, com o uso de análise comparada da expansão do Poder Judiciário em diferentes países. A judicialização da política, para os autores, é frutoda relação inevitável que se estabelece entre direito e política. Eles apresentam a judicialização do tipo from without, como a ampliação da atuação do Poder Judiciário, por meioda revisão judicial dos atos do Executivo e Legislativo. Esta seria a judicialização do tipo mais comum, estando baseada no mecanismo, cunhado nas sociedades democráticas, de checks and balances. O segundo tipo, por sua vez denominado como from within, designa a expansão dos procedimentos considerados próprios do Poder Judiciário, como a ação judicial no Executivo. Tal mecanismo refere-se à existência de três Poderes atuantes na sociedade, considerados independentes e harmônicos entre si, como forma de impedir o despotismo de um poder em particular (22).

No Brasil, essa conceituação passou a ser utilizada largamente, a exemplo de autores como Maciel e Koerner (23), que sintetizam a utilização da expressão da judicialização da política em três âmbitos. O primeiro se refere à área dos juristas, que analisam a judicialização como a obrigação legal, uma vez que o Poder Judiciário não pode se abster de julgamento quando acionado, mesmo que seja para indeferi-lo. O segundo, de caráter normativo, sintetiza que a judicialização seria o ingresso na via judicial para a resolução de determinado tema. Essa análise da judicialização entende que há uma preferência do autor, que formulou o pedido judicial pela utilização, por essa via. Por fim, o terceiro sentido refere-se à judicialização 
entendida como um processo social e político, designando essa expressão como conceito para a expansão da atuação do Poder Judiciário, bem como o aumento pela sua busca para resolução de conflitos (24).

Dentre as razões que suscitaram a expansão do Poder Judiciário, tradicionalmente se digladiam as teorias conceitualistas e funcionalistas. Exemplo da primeira é a noção de que a expansão do Judiciário é uma decorrência da positivação de direitos fundamentais no bojo das Constituições nacionais e dos tratados internacionais a partir da Segunda Guerra Mundial (22). Foi sobretudo do surgimento de uma cultura de direitos, o que reforça o argumento de Carvalho (25), que destaca a democracia como a primeira condição necessária para a judicialização de políticas públicas. No Brasil, só pôde ocorrer após a promulgação da Constituição de 1988 e a existência de direitos políticos.

Outra condição para que ocorra a judicialização é o país estar organizado com a separação dos três Poderes, cujas ações majoritárias são, no entanto, ineficientes, devido à inabilidade dessas esferas do governo em lidar com determinadas questões, como, por exemplo, as demandas sociais e os direitos individuais.

Castro (26) estabelece que a judicialização da política pública ocorre diante de uma falha do Poder Legislativo e do Poder Executivo em atender suas demandas, sendo o Poder Judiciário chamado a se pronunciar frente à insatisfação da sociedade quando há omissão na implementação da política estatal estabelecida para a tomada de ação. Historicamente, o Estado brasileiro privou grande parcela de sua população de seus direitos fundamentais (27).

No cenário brasileiro, as obras de Vianna et al (28) e Arantes (29) são imprescindíveis para desenvolver a compreensão referente à temática de judicialização de políticas no Brasil. Arantes (29) desenvolveu estudo acerca do papel do Ministério Público, tendo como eixo de análise as mudanças na estrutura e no direcionamento dessa instituição até a Constituição de 1988, ressaltando o voluntarismo político. Essa postura, segundo Arantes (29), parte do pressuposto de que a sociedade brasileira é hipossuficiente, no sentido de proteção e seguridade social. Vianna et al (28) analisam a expansão da atuação do Poder Judiciário, que se desloca para âmbitos antes relegados ao Executivo e Legislativo e estaria atuando na resolução de conflitos. Os autores apontam na direção de que o Judiciário não estaria atuando fora de seus limites.

Segundo Ventura et al (20), esse fenômeno envolve aspectos políticos, sociais, éticos e 
sanitários, que vão muito além de seu componente jurídico e de gestão de serviços públicos. A falta de conhecimento dos magistrados sobre as tecnologias em saúde e a regulação administrativa do SUS, ou seja, da própria legislação, tem levado a equívocos, sobretudo quando salvaguarda o acesso a medicamentos e terapias que não possuem evidência científica, sem garantia de eficácia, eficiência e efetividade, trazendo embutido apenas custos (30).

Por essas razões, a efetivação desse direito requer recursos financeiros e disponibilidade orçamentária, o que leva a referir dois princípios indispensáveis em razão da peculiaridade do tema: i) o princípio da reserva do possível, que parte da ideia de que a realização dos direitos sociais e prestações por parte do Estado estão subordinados a sua capacidade financeira. Assim, a prestação reclamada pelos indivíduos deve corresponder àquilo que razoavelmente seja possível esperar das possibilidades da sociedade (31); ii) o princípio do mínimo existencial, para o qual haveria um núcleo básico de direitos sociais e econômicos vinculados à noção de garantia da dignidade humana, e que deveriam ser sempre, e de imediato, tutelados (32). Essa dicotomia revela o que busca o cidadão e o que a sociedade tem a oferecer, espelhando a atual situação do direito à saúde na visão do Judiciário como um direito fundamental a ser tutelado (33).

A judicialização da saúde também pleiteia tratamentos que deveriam estar ofertados pelo SUS. Segundo Carvalho (25), na busca da via judicial para essa garantia, o tratamento para a Aids apresentou-se pioneiro nesse aspecto, servindo de base e exemplo para lides posteriores que abordavam a tutela coletiva. A proposta da terapia antirretroviral, de 1996, apresentou grande evolução no tratamento e aumento na expectativa de vida dos enfermos, todavia, o custo do tratamento era muito elevado para grande parte da população. O caminho encontrado pelos hipossuficientes para obter acesso ao tratamento foi buscar socorro no Judiciário para sanar a ineficiência do SUS nos casos concretos (3).

Observa-se que a judicialização da saúde, em sua essência, surge como uma importante ferramenta para os usuários demandarem política pública de saúde, voltada para doenças graves que acometem uma população, por meio de tutelas coletivas (25). Percebe-se que, nos casos em que as políticas públicas vigentes não atendam ao cidadão, que seja o Judiciário o seu interlocutor junto às instituições públicas, ponderando e atuando como moderador em situações de vazio existencial, o que estaria de acordo com os princípios do sistema sanitário brasileiro (34). 
Após a Constituição de 1988, foram promovidas mudanças na dinâmica de atuação dos governos locais, atribuindo aos Municípios a gestão e provisão de serviços; e aos Estados e União, a coordenação, regulação, controle e apoio técnico. Esse novo modelo federativo, apontado por Fernandes e Wilson (35) e denominado como federalismo municipalista, tinha um problema embutido, que consistia na fraca capacidade financeira e institucional dos Municípios em absorver as atribuições sociais que a Constituição lhes incumbiu, notadamente na área de saúde, o que contribui ainda mais para a ineficiência na efetivação desse direito e diretamente para o fenômeno da judicialização.

A autonomia política municipal se deu com dependência financeira de transferências e quase nenhum meio de arrecadação tributária, forçando ainda mais os estados a atender às demandas de saúde da população, independente das competências administrativas. No plano mais geral, a descentralização e a democratização do poder político no Brasil, iniciadas na década de 1980 (36,37), aumentaram a importância dos governos subnacionais. Hoje, os cidadãos têm nos poderes locais sua maior referência estatal, uma vez que a maioria das políticas sociais e as funções básicas da União, como a educação, a saúde e a segurança pública, são plenamente executadas por estados e/ou municípios, quando não formuladas e financiadas por eles. Isso acabaria por dar reforço à visão equivocada do Poder Judiciário sobre as competências administrativas dos entes, atribuindo aos Estados a responsabilidade por toda e qualquer demanda de saúde, abarcada ou não por política pública (38).

O SUS, como uma das políticas sociais do país, é um dos maiores sistemas de saúde do mundo em termos de abrangência e cobertura da população. Segundo dados da OMS, o Brasil possui população absoluta de aproximadamente 207 milhões de pessoas, com gasto total em saúde de 8,3\% (39). O Reino Unido, por sua vez, possui população de cerca de 64 milhões, com gasto total em saúde de $9,1 \%$, sendo que $87 \%$ desses gastos são direcionados somente para a Inglaterra, que apresenta uma população de aproximadamente 54 milhões de pessoas (40). Assim, apesar de possuírem gastos equivalentes, o SUS necessita cobrir uma população quase quatro vezes maior que o sistema britânico, refletindo no gasto per capita em saúde do Brasil, que é 2,5 vezes menor que no Reino Unido. No sistema britânico, a política é mais coordenada, pois tem recursos vinculados entre as três esferas, diferente da educação ou assistência social, que não possui a mesma coordenação e repasse de recursos vinculados. Já o SUS é uma política contínua e marcada por transferências intergovernamentais, cristalizada, 
do ponto de vista do path dependency3.

O financiamento é feito por meio do orçamento da seguridade social, que engloba a saúde, a previdência e a assistência social. No caso da saúde, as principais fontes de recursos são a contribuição sobre o lucro líquido (CSLL) e a contribuição para o financiamento da seguridade social (Cofins), pagas pelas empresas à União, sendo os planos de execução da saúde pública a base das atividades e das programações de cada nível do SUS. O financiamento será previsto na respectiva proposta orçamentária, sendo vedada a transferência de recursos para o financiamento de ações não previstas nos planos de saúde, exceto em situações emergenciais ou calamidade pública na área de saúde (41).

A judicialização apresenta teses antagônicas: (i) a efetivação do direito à saúde deve se dar independentemente de política pública, é o caso do HIV-Aids; (ii) a efetivação do direito à saúde só deve se dar mediante uma política pública, é o que defendem os gestores; iii) a efetivação do direito à saúde deve se dar mediante uma política pública, todavia, admitidas exceções (42). A última tese foi a posição adotada pelo Supremo Tribunal Federal (STF) quando da decisão da Suspensão de Tutela Antecipada (STA) no 175, que tratou do primeiro grande julgado envolvendo o tema do direito à saúde no STF, após a Audiência Pública no 4, convocada em 2009 também pelo STF. Promoveu-se um debate dos diversos setores envolvidos no tema da saúde pública, na busca por respostas à crescente judicialização, visto o gasto do Tesouro Nacional ser crescente com esse tema (43). As conclusões da $1^{\text {a }}$ Turma do Tribunal Regional Federal da $5^{\mathrm{a}}$ Região fixaram parâmetros judiciais a serem seguidos em ações relacionadas à essa matéria (44).

Posteriormente, ocorreu o amadurecimento em torno da discussão, e chegou-se ao RE № 855.178-S e à Tese de Repercussão Geral (Tema 793) (44):

Os entes da federação, em decorrência da competência comum, são solidariamente responsáveis nas demandas prestacionais na área da saúde, e diante dos critérios constitucionais de descentralização e hierarquização, compete à autoridade judicial direcionar o cumprimento conforme as regras de repartição de competências e determinar o ressarcimento a quem suportou o ônus financeiro (44).

\footnotetext{
${ }^{3}$ Significa que um país, ao iniciar uma trilha, tem os custos aumentados para revertê-la. Existirão outros pontos de escolha, mas as barreiras de certos arranjos institucionais obstruirão uma fácil reversão da escolha inicial. Em economia, refere-se a como escolhas e eventos aparentemente insignificantes podem ter enormes consequências para o desenvolvimento de uma economia ou mercado.
} 
Importante salientar, no que se diz respeito aos medicamentos, que o RE ํㅜ 657.718 (Tema 500) faz ressalvas específicas sobre medicamentos e registro na Anvisa, trazendo como forma de repercussão geral (45):

1. O Estado não pode ser obrigado a fornecer medicamentos experimentais. 2. A ausência de registro na ANVISA impede, como regra geral, o fornecimento de medicamento por decisão judicial. 3. É possível, excepcionalmente, a concessão judicial de medicamento sem registro sanitário, em caso de mora irrazoável da ANVISA em apreciar o pedido (prazo superior ao previsto na Lei $n=13.411 / 2016$ ), quando preenchidos três requisitos: (i) a existência de pedido de registro do medicamento no Brasil (salvo no caso de medicamentos órfãos para doenças raras e ultrarraras); (ii) a existência de registro do medicamento em renomadas agências de regulação no exterior; e (iii) a inexistência de substituto terapêutico com registro no Brasil. 4. As ações que demandem fornecimento de medicamentos sem registro na Anvisa deverão necessariamente ser propostas em face da União (45).

Tal decisão demonstra uma grande evolução sobre o reconhecimento de competência dos entes, a despeito da solidariedade, vislumbrando-se uma saída para que o Judiciário direcione o custeio das demandas para seu respectivo ente responsável. Traz também proteção aos que necessitam de medicamentos nas circunstâncias acima, ao mesmo tempo que protege os usuários de medicamentos que não se fundamentam da medicina baseada em evidências, para que não seja concedida a tutela antecipada em casos cientificamente controversos, até se esclarecerem as dúvidas técnicas pertinentes. Não é possível, ainda, fixarem-se prognósticos sobre os efeitos dessas decisões no meio médico e jurídico, mas é possível antever que, assim como ocorreu com a judicialização da saúde após o advento da STA no 175, o julgamento desses recursos paradigmáticos pelo STF e pelo STJ possui alcance limitado no horizonte temporal-tecnológico, diante da busca incessante de novas descobertas no campo médicocientífico, podendo-se apenas prever a necessidade constante de novas discussões.

\section{Metodologia}

Para analisar a judicialização no estado da Bahia, foi realizado um estudo a partir de uma abordagem qualitativa de análise, de natureza descritiva e perspectiva longitudinal (46).

Em razão da sua importância, principalmente na região Nordeste, e da viabilidade de acesso a dados e informações, foi escolhido o estado da Bahia para a realização do estudo de 
caso. De forma mais específica, podemos relacionar as seguintes motivações para o recorte geográfico de análise: i) foi verificado, na base de dados do Núcleo de Atendimento à Judicialização da Saúde ${ }^{4}$ (NAJS), um volume grande de ações judiciais demandando medicamentos e serviços de saúde, que se deve ao fato do Judiciário compreender que o Estado tem mais responsabilidade sobre as ações de saúde pública em comparação aos entes municipais e federais; ii) a existência de banco de dados, localizado no NAJS, viável, robusto e de fácil acesso à equipe da pesquisa.

Observou-se, durante as leituras preliminares, uma lacuna em trabalhos acerca de ações judiciais referentes ao direito à saúde nas regiões Norte e Nordeste $(18,47)$.

Os dados foram coletados em documentos impressos e digitais da base do NAJS, do Fundo Estadual de Saúde da Bahia (Fesba), e da Diretoria de Assistência Farmacêutica (Dasf), todos da base da Secretaria da Saúde do Estado da Bahia (Sesab). Em razão da disponibilidade de dados da base selecionada, o recorte temporal do estudo ficou definido entre os anos de 2014 a 2017, que coincidem com o período em que o NAJS reuniu as informações utilizadas na etapa de análise deste trabalho. O trabalho de coleta de dados e informações foi realizado em duas etapas. Na primeira, procurou-se verificar a evolução histórica sobre o direito a saúde, judicialização e legislação do SUS em publicações acadêmicas. Foi empreendida uma pesquisa bibliográfica para selecionar as principais publicações que abordavam os temas do trabalho, a partir de buscas nas bases de dados Scielo, Google Acadêmico e Biblioteca Virtual em Saúde, considerando um período de publicação compreendido entre 1996 a 2017.

A segunda etapa foi a realização da pesquisa documental, que utilizou, como fonte principal, o banco de dados do NAJS, local onde concentra as informações referentes à judicialização da saúde na Sesab. O banco de dados consultado é alimentado pela inclusão das ações que têm exclusivamente o estado no polo passivo, ou com outros entes, solidariamente. A tabulação de dados e informações é realizada por meio de elaboração de planilhas pelos

\footnotetext{
${ }^{4}$ Levando em consideração a extensão e as dimensões alcançadas pelas ações judiciais ao longo dos anos, as consequências aos cofres públicos e a necessidade de fortalecer a comunicação com os setores responsáveis pelo cumprimento das demandas judiciais, foi publicada, em 30 de abril de 2015, a Portaria no 453, que instituiu o Núcleo de Atendimento à Judicialização da Saúde (NAJS), setor ligado ao Gabinete do Secretário de Saúde, composto por equipe multidisciplinar voltada para atender as demandas judiciais nos seus variados contextos, no que diz respeito aos bens e serviços em saúde. No âmbito da Secretaria, cabe destacar algumas competências do referido Núcleo, dentre as quais: analisar, dinamizar e facilitar os atendimentos das demandas judiciais relacionadas à área da saúde; orientar o secretário estadual de saúde frente aos processos judiciais; e acompanhar o cumprimento das demandas judiciais seguindo as orientações da Procuradoria do Estado, subsidiando-a com informações que possam servir como base para defesa do Estado.
} 
colaboradores do NAJS, na Sesab, do qual faz parte um dos membros da equipe de pesquisadores envolvidos neste estudo. Para dados sobre os custos relacionados ao processo de judicialização, foram acessadas informações disponíveis em documentos da Dasf e do Fesba, tais como relatórios, impressos e documentos normativos.

Foi realizada uma análise a partir do dados descritivos acerca da judicialização no estado da Bahia, que permitiu apresentar a evolução das ações judiciais que determinam o fornecimento de bens de saúde - tratamentos; serviços; órteses, próteses, materiais e equipamentos (OPME); medicamentos; insumos etc. - entre 2010 e 2017, assim como o custo e os medicamentos mais demandados no ano de 2017, para propor uma reflexão sobre como esse gasto discricionário pode ocasionar a distorção na organização das competências dos entes dentro do SUS e seu desfecho no orçamento da saúde.

Um fator limitante para a coleta de dados fora do NAJS - para cruzamento e melhor espelhamento - é a inexistência de um banco de dados de referência no Tribunal de Justiça da Bahia e no Tribunal Regional Federal da 1ㅡㅡ Região, onde poderiam ser realizadas pesquisas mais fidedignas (7). Outro fator importante é a ausência de padronização no cadastramento da ação judicial referente à saúde, como a correta descrição do objeto da ação, que pode ser feita de diversas maneiras pelo patrono. Pesquisas que dialoguem com o direito, a saúde e com a Administração Pública precisam ser desenvolvidas, visto que o assunto é de suma importância e necessita entrar na agenda governamental para propositura de ações e estratégias

\section{Resultados e discussão}

O gráfico 1 representa a curva ascendente com os números de todas as ações de saúde contra o Estado, sendo esse o único ente acionado ou em solidariedade com um ou mais de um ente e o número de processos judiciais referentes a Assistência Farmacêutica no estado da Bahia 
Gráfico 1. Judicialização da saúde pública no estado da Bahia de 2014 a 2017

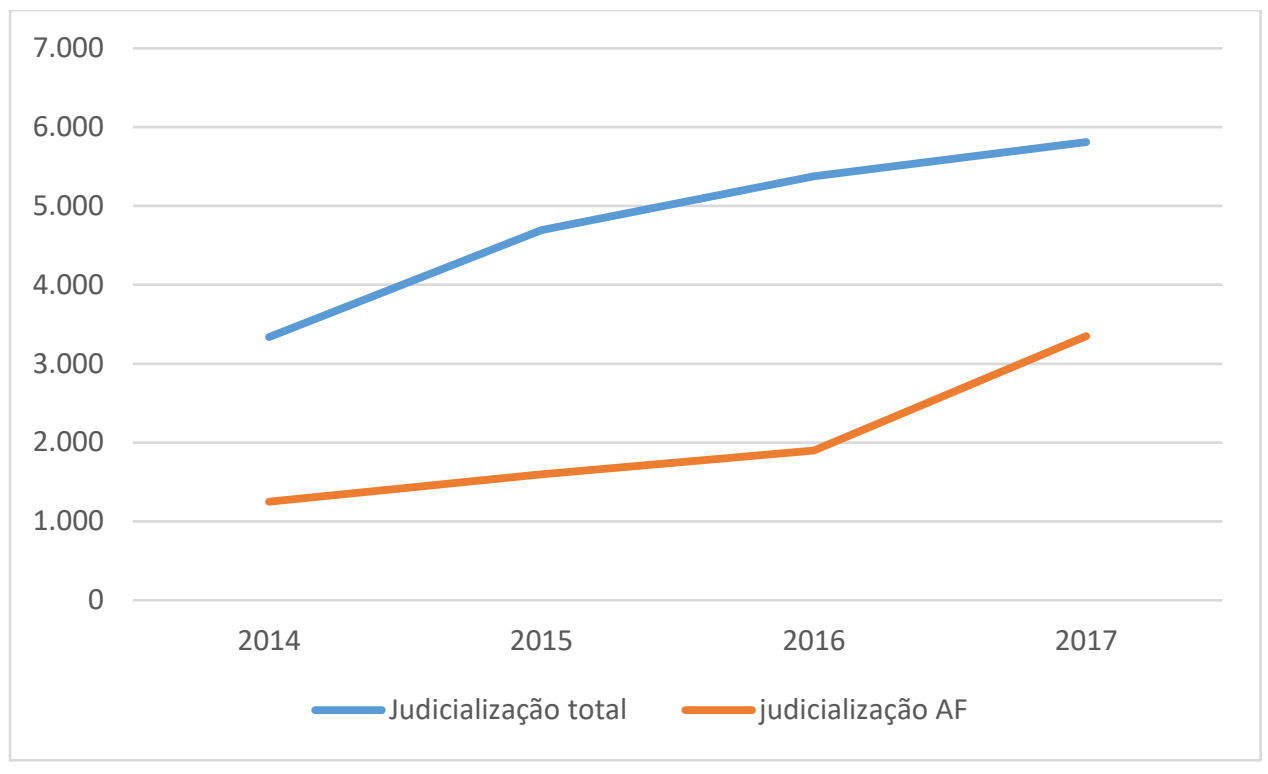

Fonte: elaborado pelas autoras.

É inegável e notória a tendência de crescimento das demandas, estando de acordo com a literatura existente e com os dados do próprio CNJ na área da saúde (7).

Da análise das demandas pleiteadas, sejam elas relativas a medicamentos ou serviços, percebe-se que tratam de tutelas individuais, refletindo pouco ou nenhum impacto sob a forma de política pública (11-18). Foram identificadas, no universo das ações sobre assistência farmacêutica contra o estado da Bahia, apenas oito ações civis públicas.

No gráfico 2, evidencia-se a real problemática gerada pela judicialização, o custo despendido pelo Estado para custeio de ações judiciais relacionadas à assistência farmacêutica, comparado com os valores destinados aos componentes básico e especializado da assistência farmacêutica. 
Gráfico 2. Valores gastos pelo estado da Bahia com ações judiciais relacionados à assistência farmacêutica

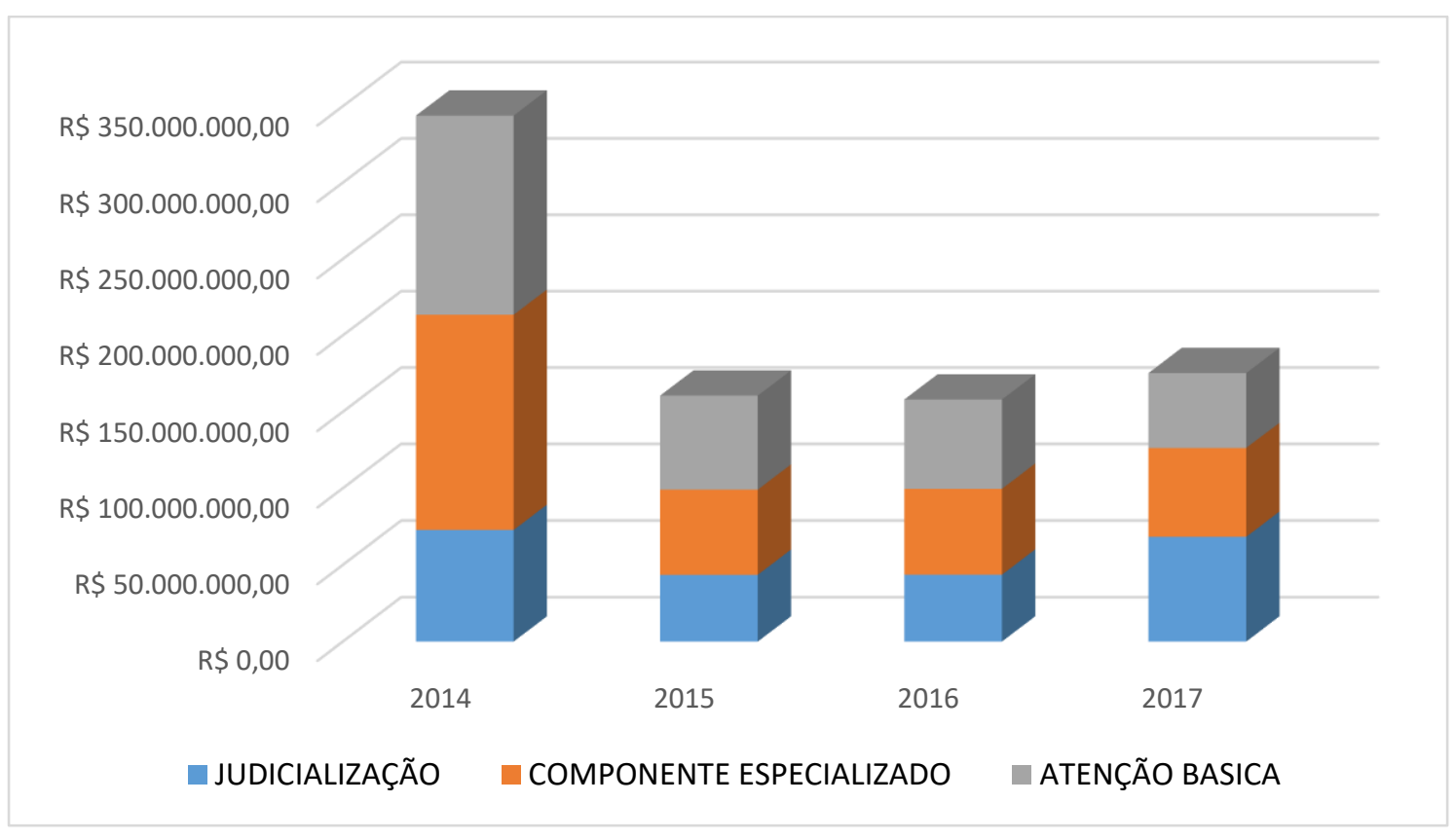

Fonte: elaborado pelas autoras.

Pelo Censo do IBGE de julho de 2017 (48), a Bahia tem cerca de 15,28 milhões de habitantes; e considerando que o orçamento total para medicamentos em 2017 foi de $R \$ 175.331,407,00$, os pacientes com decisões judiciais fizeram jus, per capita, a $R \$ 29.221,90$, enquanto que, para a população em geral, ficariam cerca de $R \$ 7,01$ ou seja, menos de $1 \%$ da população ficou com $38,9 \%$ de todo o orçamento para medicamentos, enquanto $99 \%$ dividiu os $61,1 \%$ restantes (49)

Esse fenômeno faz com que, para atender a demanda não prevista, o gestor utilize de seu poder discricionário para fazer cumprir o que é determinado pelo Judiciário. Segundo Sarlet e Figueiredo (50), a disponibilidade de recursos está localizada no campo discricionário das decisões governamentais e parlamentares, sintetizadas no orçamento público, assim como o que é razoável depende da decisão referida e da ponderação por parte do legislador. O poder da discricionariedade é dado à Administração Pública para que possa agir livremente, com base nos limites da lei, utilizando-se de critérios específicos, como a conveniência e a oportunidade, a justiça, a razoabilidade, a equidade e o interesse público. Quando a judicialização é em prol da coletividade, a discricionariedade se aplica perfeitamente, mas não para a realidade apresentada, pois trata-se quase que exclusivamente de demandas que pleiteiam interesses 
individuais. No gráfico 3, estão os medicamentos mais demandados em 2017.

Gráfico 3. Medicamentos mais demandados judicialmente em desfavor do estado da Bahia em 2017

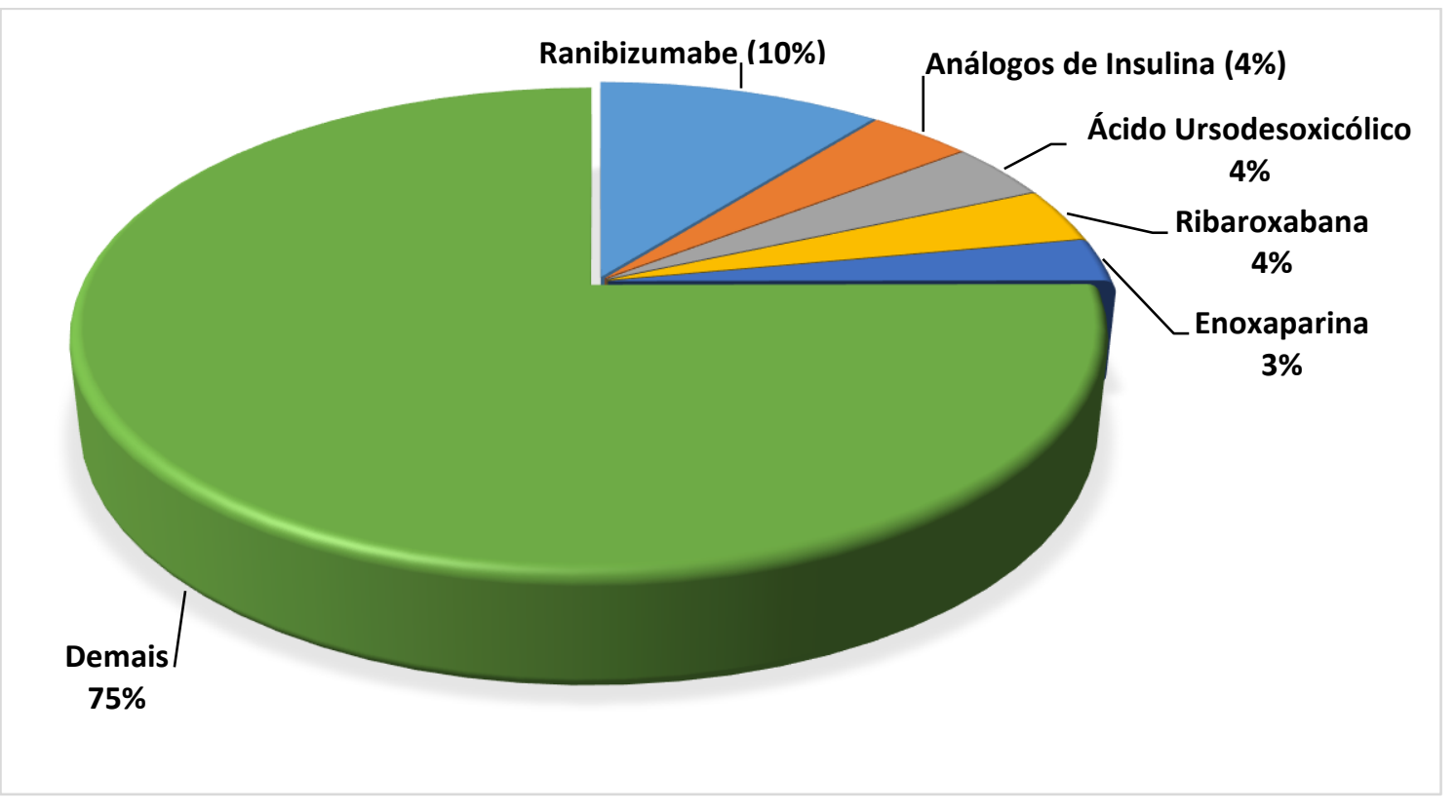

Fonte: elaborado pelas autoras.

Percebe-se que há uma diversidade nos pedidos de medicamentos. Foram encontrados mais de 620 tipos diferentes de medicamentos, e os mais demandados estão fora das listas oficiais ou foram prescritos fora dos PCDTs.

É sabido que o avanço tecnológico nas últimas décadas proporcionou oferta de novas tecnologias, gerando melhorias na saúde da população. Todavia, é necessário que haja a promoção do uso racional dessas novas tecnologias $(51,52)$. As decisões devem ser fundamentadas na medicina baseada em evidências e na respectiva política pública, devido ao grande impacto orçamentário que podem representar e nas possíveis consequências aos próprios pacientes com o uso de medicamentos ou tratamentos inapropriados, já que nem todas as inovações agregam valor ao atendimento do paciente, quando não apenas custos (30).

$\mathrm{Na}$ tabela 1, são apresentados os valores relativos aos dez medicamentos que mais impactaram no orçamento destinado à assistência farmacêutica em 2017. 
Tabela 1. Valores gastos relacionados à assistência farmacêutica (AF) em 2017

\begin{tabular}{lcllc}
\hline Medicamento & $\begin{array}{l}\text { Dispensação } \\
\text { mensal do } \\
\text { medicamento }\end{array}$ & Valor unitário & Custo mensal & $\begin{array}{c}\text { Impacto no } \\
\text { orçamento } \\
\text { mensal de AF }\end{array}$ \\
\hline Ranibizumabe & 451 & $\mathrm{R} \$ 3.577,21$ & $\mathrm{R} \$ 1.613 .321,71$ & $14,82 \%$ \\
Proteína C & 200 & $\mathrm{R} \$ 3.471,60$ & $\mathrm{R} \$ 694.320,00$ & $6,38 \%$ \\
Eculizumabe & 28 & $\mathrm{R} \$ 20.102,34$ & $\mathrm{R} \$ 562.865,52$ & $5,17 \%$ \\
Brentuximabe & 28 & $\mathrm{R} \$ 15.850,11$ & $\mathrm{R} \$ 443.803,08$ & $4,08 \%$ \\
Imunoglobulina & 548 & $\mathrm{R} \$ 735,00$ & $\mathrm{R} \$ 402.780,00$ & $3,70 \%$ \\
Galsulfase & 79 & $\mathrm{R} \$ 4.691,67$ & $\mathrm{R} \$ 370.641,93$ & $3,40 \%$ \\
Sofosbuvir & 148 & $\mathrm{R} \$ 2.420,05$ & $\mathrm{R} \$ 358.167,40$ & $3,29 \%$ \\
Sorafenibe & 3.480 & $\mathrm{R} \$ 88,77$ & $\mathrm{R} \$ 308.919,60$ & $2,84 \%$ \\
Idursulfase & 56 & $\mathrm{R} \$ 5.112,10$ & $\mathrm{R} \$ 286.277,60$ & $2,63 \%$ \\
Ibrutinib & 690 & $\mathrm{R} \$ 399,97$ & $\mathrm{R} \$ 275.979,30$ & $2,53 \%$ \\
\hline
\end{tabular}

Fonte: elaborado pelas autoras.

Os dados demonstram que $30 \%$ dos medicamentos requeridos judicialmente têm seu fornecimento sob competência da União, por meio do componente especializado da assistência farmacêutica, porém, pelo fato do paciente não se enquadrar nos critérios de inclusão descritos pelos protocolos clínicos e diretrizes terapêuticas (PCDT), judicializa-se a demanda, tendo o Estado como fornecedor do medicamento e arcando com o custo.

A jurisprudência recente do STF acerca do tema, inserta no RE no 855.178 (44), mantém a tese da responsabilidade solidária dos entes da Federação nas demandas prestacionais na área da saúde, mas inova em dois pontos: i) permite que a autoridade judicial direcione o cumprimento da decisão ao ente legalmente responsável, conforme a repartição de competências; e ii) permite ao magistrado determinar o ressarcimento ao ente que suportou a obrigação indevidamente (44).

No caso da judicialização da assistência farmacêutica do estado da Bahia, essa decisão do STF poderá trazer repercussões positivas, se devidamente aplicada.

Importante ponderar que o Poder Judiciário parece ainda não ter se organizado na 
percepção de que não se pode aplicar a mesma metodologia para solução de todas essas demandas - medicamentos, tratamentos, leitos etc. É necessário, em um primeiro momento, compreender a diferença entre julgar o pedido de dispensação de um medicamento já previsto e garantido em políticas públicas do SUS e o pleito de um medicamento de alto custo não previsto (53).

\section{Conclusão}

O que se quer levantar no presente trabalho não é a questão do direito à saúde, pois já está garantido na Constituição, mas que se chegue a um equilíbrio entre o que está se pleiteando e o que o SUS tem a oferecer. A judicialização no estado da Bahia segue a tendência nacional de aumento, sem que se vislumbre uma adequada discussão entre o Poder Público, o Judiciário e a sociedade.

Com isso, chega-se às seguintes inferências: ao usuário, interessa que a tecnologia em saúde atenda a seu caso concreto; ao gestor, interessa que a incorporação e uso da tecnologia tenham eficácia e sejam efetivos e eficientes, a partir dos critérios da melhor prática científica, por meio da medicina baseada em evidências, e que caibam no orçamento. Por fim, cabe ao Judiciário mediar a melhor solução possível, uma vez que é provocado, tendo sempre em mente a finitude dos recursos, as políticas públicas vigentes, o interesse comum e o interesse do cidadão.

De pronto, já se observa que, de um lado, há o direito à saúde, com a proposta de ser acessível universalmente e em qualquer nível de atenção. De outro, os limites intrínsecos das organizações e dos recursos orçamentários e financeiros para a realização da política pública. Assim, resta ao SUS, as escolhas alocativas - para as quais se deve primar pela eficiência, em fazer melhor com menos recursos.

O sistema, da forma que está seguindo, perde seu caráter universal, sendo necessárias análises e inclusão do tema na agenda política, provocando discussões sérias e realistas. Por ser a produtora de ações efetivas, a judicialização da política de saúde não deve servir apenas para sobrecarregar ainda mais um Judiciário já sobrecarregado, mas servir para a promoção de mudanças que atendam ao cidadão, com políticas públicas realistas e tendo sempre a perspectiva de um orçamento cada vez menor.

A judicialização da saúde tem magnitude e perfil reais desconhecidos, dificultando o 
planejamento do Judiciário e do Executivo, e é um processo intersistêmico, que interfere no relacionamento entre Executivo e Judiciário e entre o sistema político e o jurídico. Apesar de sua importância e atualidade, não há clareza de sua real dimensão, dos custos envolvidos nem de suas consequências para o futuro do sistema de saúde.

Como contribuição, o estudo apresenta o impacto no estado da Bahia, demonstrando que também existem falhas na política pública, podendo ajudar gestores na tomada de decisões, além de servir de motivador para pesquisas futuras, devido à escassez de pesquisas no Nordeste e à ausência de publicações referentes ao estado da Bahia. Por fim, em situações de falha na política pública, que venha a ser o Judiciário o interlocutor para atender a demanda de saúde do usuário. Os recentes posicionamentos do STF diante do fenômeno vislumbram algum alento para o problema no Estado, pois, conforme demonstrado, o grande custo da judicialização é referente a medicamentos fora das listas oficiais, mas que se adéquam aos critérios estabelecidos pelo STF, podendo seu custeio ser direcionado para a União.

\section{Referências}

1. Organização Mundial de Saúde. World Health Report 2002: reducing risks, promoting healthy life. Genebra: 2002. Disponível em: http://www.who.int/whr/previous/en/index.html [Acesso em 28.set.2019].

2. BRASIL. Lei ㄲo 8.080 , de 19 de setembro de 1990. Dispõe sobre as condições para a promoção, proteção e recuperação da saúde, a organização e o funcionamento dos serviços correspondentes e dá outras providências. Diário Oficial da República Federativa. Brasília, DF, 20 set. 1990.

3. Galvão J. A política brasileira de distribuição e produção de medicamentos anti-retrovirais: privilégio ou um direito? Cad. Saúde Pública, Rio de Janeiro, v. 18, n. 1, p. 213-219, fev. 2002.

4. Carvalho ER. Em busca da judicialização da política no Brasil: apontamentos para uma nova abordagem. Revista de Sociologia Política, n. 23, 2004.

5. Silva L. Judicialização da saúde: em busca de uma contenção saudável. Disponível em: https://nandaninna.jusbrasil.com.br/artigos/179349219/judicializacao-da-saude-em-buscade-uma-contencao-saudavel [Acesso em 28.set.2019].

6. Wang DWL, Vasconcelos NP, Oliveira VE, Terrazas FV. Os impactos da judicialização da saúde no município de São Paulo: gasto público e organização federativa. Rev. Adm. Pública, Rio de Janeiro, v. 48, n. 5, p. 1191-1206, out. 2014. 
7. Conselho Nacional de Justiça. Justiça em Números 2018: ano-base 2017. Brasília: CNJ, 2018. Disponível em http://www.cnj.jus.br/programas-e-acoes/pj-justica-em-numeros [Acesso em: 15.maio.2019].

8. Brasil. Relatório de cumprimento da Resolução CNJ no 107. Brasília (DF): Conselho Nacional de Justiça, 2014. Disponível em: http://www.cnj.jus.br/images/programas/Forumdasaude/ demandasnostribunais.FórumSaude.pdf [Acesso em: 15.maio.2019].

9. Brasil. Relatório de cumprimento da Resolução CNJ no 107. Brasília (DF): Conselho Nacional de Justiça; 2011. Disponível em: http://ww.cnj.jus.br/images/programas/Forum dasaude/relatorio_atualizado_da_resolucao107.pdf [Acesso em: 15.maio.2019].

10. Cruz F. Judicialização na saúde cresce $130 \%$ no país, mostra estudo. Agência Brasil.18.mar.2019. Disponível em: http://agenciabrasil.ebc.com.br/justica/noticia/201903/judicializacao-na-saude-cresce-130-no-pais-mostra-estudo [Acesso em: 15.maio.2019].

11. Messeder AM, Osorio de Castro CGS, Luiza VL. Mandados judiciais como ferramenta para garantia do acesso a medicamentos no setor público: a experiência do Estado do Rio de Janeiro, Brasil. Cad. Saúde Pública, Rio de Janeiro, v. 21, n. 2,p. 525-534, abr. 2005.

12. Borges DCL, Ugá MAD. Conflitos e impasses da judicialização na obtenção de medicamentos: as decisões de 1 a instância nas ações individuais contra o Estado do Rio de Janeiro, Brasil, em 2005. Cad Saude Publica. 2010;26(1):59-69. http://dx.doi.org/10.1590/S0102-311X2010000100007. PMid:20209210 [Acesso em: 30 abr. 2019].

13. Chieffi AL, Barata RB. Judicialização da política pública de assistência farmacêutica e eqüidade. Cad. Saúde Pública, Rio de Janeiro, v. 25, n. 8, p. 1839-1849, ago. 2009.

14. Romero LC. Judicialização das políticas de assistência farmacêutica: o caso do Distrito Federal. Brasília: Consultoria Legislativa do Senado Federal; 2008. (Textos para Discussão, 41).

15. Diniz D, Machado TRC, Penalva J. A judicialização da saúde no Distrito Federal, Brasil. Ciência \& Saúde Coletiva, Rio de Janeiro, v. 19, n. 2, p. 591-598, fev. 2014.

16. Machado MAA, Acurcio FA, Brandão CMR, Faleiros DR, Guerra Jr AA, Cherchiglia ML, et al. Judicialização do acesso a medicamentos no Estado de Minas Gerais, Brasil. Rev. Saúde Pública, São Paulo, v. 45, n. 3, p. 590-598, jun. 2011.

17. Pereira JR, Santos RI, Nascimento Junior JM, Schenkel EP. Análise das demandas judiciais para o fornecimento de medicamentos pela Secretaria de Estado da Saúde de Santa Catarina nos anos de 2003 e 2004.Ciência \& Saúde Coletiva, Rio de Janeiro, v. 15, supl. 3, p. 3551-3560, nov.2010. 
18. Vasconcelos FJL, Dias MSA, Saraiva MJG, Silva MMS. Judicialização da Saúde: Análise de ações judiciais demandadas na comarca de Sobral, Ceará. SANARE, Sobral - v.16 n. 02, p. 06-13, jul./dez. 2017.

19. EC n.o 95, de 2016. Altera o Ato das Disposições Constitucionais Transitórias, para instituir o Novo Regime Fiscal, e dá outras providências. Diário Oficial da República Federativa. Brasília, DF, 16. Dez. 2016. Disponível em: https://www2.camara.leg.br/legin/fed/ emecon/2016/emendaconstitucional-95-15-dezembro-2016-784029-publicacaooriginal151558-pl.html [Acesso em: 17.fev.2018].

20. Ventura M, Simas L, Pepe VLE, Schramm FR. Judicialização da saúde, acesso à Justiça e a efetividade do direito à saúde. Physis, Rio de Janeiro, v.20, n.1, 2010.Disponível em: http://www.scielo.br/scielo.php?script=sci_arttext\&pid=S0103-73312010000100006\&lng $=$ pt\&nrm=isoi [Acesso em: 17.fev.2016].

21. Vianna LW, Burgos MB, Salles PM. Dezessete anos de judicialização da política. Tempo Social, Revista de Sociologia da USP, v. 19, n. 2, p. 39-85, nov. 2007.

22. Tate CN, Vallinder T. The global expansion of judicial power. Nova York: New York University Press, 1995.

23. Maciel DA, Koerner A. Sentidos da judicialização da política: duas análises. Lua Nova, São Paulo, n. 57, p. 113-133, 2002.

24. Brandão R. A judicialização da política: teorias, condições e o caso brasileiro. Revista de Direito Administrativo, Rio de Janeiro, v. 263, p. 175-220, maio/ago 2013.

25. Carvalho RK. A judicialização do acesso à saúde no brasil: O caso HIV-AIDS. Monografia apresentada como requisito para a obtenção do grau de especialista em Preparação para a Magistratura na Universidade do Extremo Sul Catarinense, Criciúma, março de 2007.

26. Castro MF. O Supremo Tribunal Federal e a judicialização da política. São Paulo, v.12, n. 34, julho, 1997.

27. Sarlet IW. A eficácia dos direitos fundamentais. 11. ed. Porto Alegre: Livraria do Advogado, 2012.

28. Vianna LW (organizador). A judicialização da política e das relações sociais no Brasil. Rio de Janeiro: Revan, 1999.

29. Arantes RB. Ministério Público e Política no Brasil. São Paulo: Sumaré, 2002.

30. Santos L (organizador). Judicialização da saúde no Brasil, 2014, Saberes.

31. Wang DWL. Escassez de recursos, custos dos direitos e reserva do possível na jurisprudência do STF. Rev. Direito GV, São Paulo, v. 4, n. 2,p. 539-568, dez. 2008. 
32. Sarlet IW, Figueiredo MF. Reserva do possível, mínimo existencial e direito à saúde: algumas aproximações. Revista de Doutrina da 4를 Região, Porto Alegre, n. 24, jul. 2008. Disponível em http://www.revistadoutrina.trf4.jus.br/artigos/edicao024/ingo_mariana.html [Acesso em: 30.abr. 2019].

33. Alexy R. Teoria dos direitos fundamentais. 5. ed. São Paulo: Malheiros, 1982.

34. Paim JS. Reforma Sanitária Brasileira: avanços, limites, perspectivas. in: Matta GC, Lima JCF (orgs). Estado, Sociedade e Formação Profissional em Saúde: contradições e desafios em 20 anos de SUS. Rio de Janeiro: Fiocruz/EPSJV, 2008, p. 91-122.

35. Fernandes ASA, Wilson RH. Mudança Institucional e Gestão Metropolitana no Brasil: O Municipalismo Autárquico e as Finanças Municipais Metropolitanas. Revista de Administração Pública - RAP (Impresso), v. 47, p. 777-800, 2013.

36. Abrucio FL. Os barões da Federação: os governadores e a redemocratização brasileira. São Paulo: Hucitec/USP, 1998.

37. Abrucio FL. Reforma do Estado no federalismo brasileiro: a situação das administrações públicas estaduais. Revista de Administração Pública - RAP, Rio de Janeiro, v.39, n.2, p.401-420, mar./abr. 2005.

38. Arretche M. Estado federativo e políticas sociais: determinantes da descentralização. Rio de Janeiro: Revan, 2000.

39. Nicoletti MA, Faria TM. Análise comparativa dos sistemas de saúde brasileiro e britânico na atenção básica. Infarma, Ciências Farmacêuticas. 10.14450/2318-9312.v29.e4.a2017. p. 313-327.

40. United Kingdom. National Health Service (NHS Choices). The NHS in England. [legislation in Internet]. 2016. Disponível em: http://www.nhs.uk/NHSEngland/ thenhs/about/Pages/overview.aspx [Acesso em: 12.jul.2019].

41. CONASS. Desafio: concretização do direito à saúde pública no Brasil Simon LC. Direito à Saúde, da coleção Para Entender a Gestão do SUS: CONASS, 2015.

42. TCU e Estados apontam aumento dos gastos com a judicialização da saúde. Disponível em: http://www.cnj.jus.br/noticias/cnj/85911-tcu-e-estados-apontam-aumento-dos-gastoscom-a-judicializacao-da-saude [Acesso em: 12.jul.2019].

43. Schulze CJ. STF Fixa novos parâmetros para a judicialização da saúde. Emporiodedireito.com.br. 30 maio 2016. Disponível em https://emporiododireito.com.br/ leitura/stf-fixa-novos-parametros-para-a-judicializacao-da-saude-por-clenio-jair-schulze [Acesso em: 30.nov. 2018]. 
44. Brasil. Supremo Tribunal Federal. Recurso Extraordinário 855.178-SE. Recorrente: União Federal. Recorrido: Maria Augusta da Cruz Santos. Relator: Ministro Luiz Fux. Brasília, 22.mai.2019. Disponível em: http://portal.stf.jus.br/processos/detalhe.asp? incidente $=4678356$ [Acesso em 28.set.2019].

45. Brasil. Supremo Tribunal Federal. Recurso Extraordinário 657.718-MG. Recorrente: Alcirene de Oliveira. Recorrido: Estado de Minas Gerais. Relator: Ministro Marco Aurélio Mello. Brasília, 22.mai.2019. Disponível em: http://portal.stf.jus.br/processos/ detalhe. asp?incidente $=4143144$. [Acesso em 28.set.2019].

46. Gil AC. Como elaborar projetos de pesquisa. 6. ed. São Paulo: Atlas, 2017.

47. Nunes CFO, Ramos Júnior AN. Judicialização do direito à saúde na região Nordeste, Brasil: dimensões e desafios. Cad. Saúde Colet., Rio de Janeiro, v.24, n. 2, p. 192-199, 2016.

48. IBGE. Cidades e Estados. Disponível em: https://www.ibge.gov.br/cidades-eestados/ba/.html? [Acesso em: 30 abr. 2019].

49. Sarlet IW. A eficácia dos direitos fundamentais. 11. ed. Porto Alegre: Livraria do Advogado, 2012.

50. Núcleo de Atendimento à Judicialização da Saúde. Processos PGENET [planilha]. Salvador; 2017.

51. Capucho HC, Salomon FCR, Vidal AT, Louly PG, Santos VCC, Petramale CA. Incorporação de Tecnologias em saúde no Brasil: novo modelo para o Sistema Único de Saúde. Boletim do Instituto de saúde, v.13, n.3, p.215-222, jul.2012.

52. Ministério da Saúde. Política Nacional de Gestão de Tecnologias em Saúde, Brasília, 2010.

53. Neto HM. A regra de solidariedade dos entes federados na área da saúde e sua atual interpretação pelo Supremo Tribunal Federal. Cad. Ibero-amer. Dir. Sanit., Brasília, 8(3): jul./set., 2019. http://dx.doi.org/10.17566/ciads.v8i3.569 